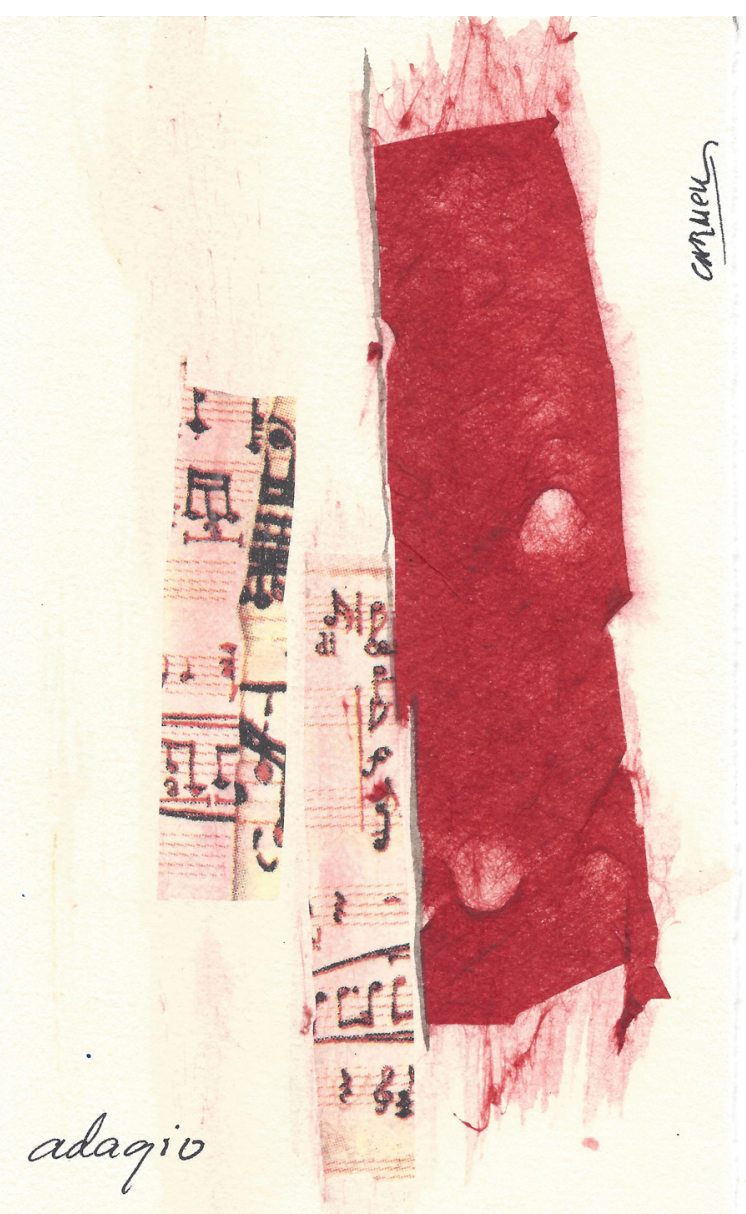


AUTOR: Carmen Franco 


\title{
Unha proposta de análise dos projected spaces en La busca de Pío Baroja
}

\author{
Laura Caamaño Pérez \\ [Recibido, 4 setembro 2019; aceptado, 11 novembro 2019] \\ http://dx.doi.org/10.15304/bgl.55.6261
}

RESUMO Partindo dos estudos literarios comparados, nomeadamente, da Xeografía Literaria, ofrécese unha proposta de análise dos denominados projected spaces, termo acuñado por Barbara Piatti, en La busca de Pío Baroja. Tendo en conta que se trata dunha novela na que a xeografía urbana da capital madrileña cobra especial relevancia debido á grande cantidade de referencias topográficas que caracterizan o espazo da obra, préstase atención ao estudo dos "espazos proxectados" que aparecen na novela. En primeiro lugar, ofrécese unhas breves consideracións sobre o estado da cuestión das Humanidades espaciais, para logo centrarnos no corpo do artigo: caracterizar o espazo de Madrid do século XIX e identificar e analizar os diferentes espazos proxectados que teñen como desencadeante o diálogo entre os personaxes.

PALABRAS CHAVE: Xeografía Literaria; projected spaces; Barbara Piatti; La busca; xeografía urbana.

ABSTRACT On the basis of Comparative Literary Studies, in particular, Literary Geography, it is offered a proposal for analysing the projected spaces, a term coined by Barbara Piatti, in La busca by Pío Baroja. Considering that it is a novel in which urban geography of Madrid is especially important because of the large number of topography references which characterize the space in the work, special attention is given to projected spaces studies in the novel. Firstly, brief considerations about the state of the question in space Humanities; afterwards, in the main body of the paper it will be characterized the space of $19^{\text {th }}$ century Madrid and the different projected spaces which triggers the dialogue between characters will be analysed.

KEYWORDS: Literary Geography; projected spaces; Barbara Piatti; La bus$c a$, urban geography.

La narrativa en sí es una forma de trazar un mapa, organizando la información obtenida de la vida en abstracto para obtener patrones reconocibles, bajo el entendido que el producto final es ficticio, una mera representación de espacio y lugar, cuya función es ayudar al «espectador» o cartógrafo, lector o escritor, a hacer sentido del mundo

(Tally Jr., 2012: 4). 


\section{Introdución}

No pasado quedaron xa as fronteiras que separaban as relacións entre xeografía e literatura. De entre os estudos que hoxe existen sobre xeografía e cartografía literarias (Neal Alexander, 2015; Tally Jr., 2012; Tang, 2008; Thacker, 2005; Turchi, 2004, entre outros), partimos dun dos traballos máis recentes de Barbara Piatti, Anne-Kathrin Reuschel e Lorenz Hurni titulado "Dreams, Longings, Memories - Visualising the Dimension of Projected Spaces in Fiction" (2013) por ser considerado unha referencia inescusábel no eido das Humanidades espaciais. Nel ofrécese unha proposta de clasificación dos distintos espazos ficcionais na que se establecen cinco grandes categorías: settings (lugares nos que acontece a acción); zones of action ("zonas de acción”); topographical markers (lugares que xa foron mencionados na obra); routes of character (rutas ou traxectos que irán realizando os distintos personaxes ao longo da novela) e, por último, projected spaces, definidos así pola propia Piatti (2013: 4):

Spatial objects which are not physically accessed by the main characters, but called up in the mode of memories, dreams (in-cluding daydreams and nightmares), longings and many others such as hallucinations, drug experiences etc. In short: They are constructed in the minds and imaginations of fictional characters, mostly via a triggering element such as another place, a picture, a scent, an object, a word or sen-tence etc. They can be seen as genuinely literary concept - some projected spaces feature inherent movie-like qualities, but no other art form offers such a wide range of techniques to create projected spaces than literature.

Así, tendo en conta a definición proposta por Piatti, os espazos proxectados corresponderíanse con aqueles lugares evocados polos personaxes a partir de lembranzas, soños ou fabulacións. Lugares construídos na imaxinación dos personaxes a raíz dun desencadeante (un obxecto, unha carta, un diálogo, etc.), un elemento responsábel da proxección espacial do personaxe, pasando de estar nun lugar concreto para situarse noutro evocado.

Este traballo céntrase na identificación e análise deste tipo de espazos de ficción na novela La busca do escritor Pío Baroja Baroja (Donostia, 18721956), publicada orixinalmente no 1904. Todos estes espazos proxectados teñen como desencadeante o diálogo. Tendo en conta que se trata dunha novela na que a xeografía urbana da capital madrileña cobra especial relevancia, a proxección espacial deste tipo de lugares teñen moito interese dende o 
punto de vista dos estudos literarios comparados en xeral, e dende a xeografía e cartografía literarias, en particular.

\section{A Xeografía Literaria. A propósito dos estudos xeográficos literarios}

A Xeografía Literaria, que xorde a comezos do século XX, céntrase no estudo do espazo literario. Segundo o investigador compostelá Fernando Cabo Aseguinolaza (2004: 27), neste período ten lugar unha mudanza importante dende o punto de vista epistemolóxico, xa que o espazo "parece haber cobrado el protagonismo que se le hurta a la temporalidad y a otras categorías vecinas". Neste marco da Xeografía Literaria encádranse os estudos cartográficos literarios ou, o que é o mesmo, a Cartografía Literaria, unha subdisciplina que pretende ofrecer un método para a análise da xeografía na literatura a través da elaboración de mapas. Así, en palabras de Alba Rozas Arceo (2015: 13-14):

A cartografía literaria tradicional baséase na concepción de que gran parte da ficción se refire ao mundo real, denominado xeoespazo, a través de moi diversas opcións, coma o uso de topónimos identificables ou o desenvolvemento de amplas descricións de espazos e lugares existentes [...]. En definitiva, o mapeo da ficción debe posibilitar un maior entendemento do funcionamento da ficción.

Á altura destas consideracións, o profesor norteamericano Robert T. Tally Jr. en Sobre la cartografía literaria (2012: 3) pon de relevo a función cartográfica das obras literarias:

Trazar el mapa establece un marco significativo para el sujeto, con puntos de referencia específicos que ayudan a pensar sobre sí mismo y sobre el lugar propio en el espacio social más amplio. Igualmente, las narrativas sirven para dar sentido, o darle forma, al mundo en cuestiones de significación. En ese caso, las obras literarias tienen una función cartográfica de crear figurativa o alegóricamente una representación del espacio social, en un sentido amplio. A esto es a lo que yo llamo cartografía literaria.

Se se fai un percorrido pola traxectoria histórica do campo das Humanidades espaciais e dos estudos xeoliterarios, tanto Neal Alexander (2015) como Barbara Piatti, Hans Rudolf Bär, Anne-Kathrin Reuschel, Lorenz Hurni e William Cartwright (2009) aluden á obra de William Sharp intitulada Lite- 
rary Geography publicada en 1904 por ser considerada o máximo referente da Xeografía Literaria. Á súa vez, cómpre mencionar tamén a relevancia do traballo de Franco Moretti (1999), no que distinguía dúas perspectivas dentro da disciplina dos estudos xeoliterarios: por unha banda, o estudo do espazo na literatura e, por outra, o estudo da literatura no espazo.

Entre os traballos de investigación que se están a desenvolver na actualidade no campo das Humanidades espaciais destaca "Compostela geoliteraria", inserido no proxecto de investigación "La proyección del lugar: Compostela en su imaginario geoliterario (1844-1926). Sistemas de Información Geográfica y Humanidades Espaciales" (FFI2013-41361-P), desenvolvido pola Universidade de Santiago de Compostela en colaboración coa Universidade de Estremadura, baixo a coordinación do catedrático de Teoría da Literatura e Literatura Comparada Fernando Cabo Aseguinolaza.

\section{Madrid como espazo literario de ficción en La busca}

O espazo que se recrea na novela do escritor Pío Baroja (Donostia,1872Madrid,1956) La busca é o Madrid de finais do século XIX. Este período propiciou "la emergencia de una novela que quiere dar cabida a las múltiples representaciones del espacio de la ciudad, auténtico microcosmo metafórico del país" (Hibbs, 2012: 281). Ademais de Pío Baroja, outros autores representativos como Benito Pérez Galdós, Leopoldo Alas ou Emilia Pardo Bazán elixiron para escenario das súas novelas a cidade de fins de século (Hibbs, 2012: 282). Pola súa parte, a doutora en Lingua e Cultura Eva Orts Agulló (2016: 52) considera que o autor de La busca, "se convierte en un nostálgico retratista de la ciudad a la busca del detalle único, característico y distintivo". Para a especialista Alba Rozas Arceo (2015: 18), “corresponde á xeografía literaria demostrar que a dimensión espacial dos textos ficcionais pode ser a chave para a comprensión do argumento”.

No Madrid do século XIX onde se sitúa a acción distínguense tres ambientes fundamentais: o interior da cidade, onde está a casa de hóspedes de Dona Casiana, da que sairá o protagonista cara ás aforas; o ensanche cos seus arrabaldes; e o extrarradio, no que terán lugar as andainas do protagonista Manuel cos golfos que viven nas marxes da capital. Polo tanto, o espazo narrativo "no se trata de un mero marco en el que se desarrolla la acción, sino 
que el espacio es un elemento esencial que [...] desempeña un papel decisivo en la configuración de los personajes y de la propia historia" (Celma Valero e González, 2010: 1). Pola súa parte, a estudosa vasca Iraitz Urkulo (2012: 269) considera que "el espacio fundamental retratado en La busca es el llamado cinturón de Madrid, que no es otro que la zona de chabolas que rodea a la creciente ciudad industrial". O innegábel valor documental deste tipo de literatura baroxiana é salientada por Urkulo (2012: 257) cando afirma que "En La busca da la sensación en determinados momentos del argumento de que se concede una mayor importancia al espacio urbanístico que a la personalidad de los personajes".

Juan Ma Marín Martínez, no limiar da súa edición de 2010, analiza as descricións que Pío Baroja elabora do Madrid naquela altura e pon de relevo a importancia que adquire a coordenada espacial na novela, tratándose dun "componente importante del relato barojiano, en cuya descrición, el escritor emplea una acertada técnica impresionista: elige sólo algunos datos de la realidad, aquellos que mayor capacidad evocadora puedan tener" (Baroja, 2010: 100-101). Así, o feito de narrar tamén pode ser interpretado como unha maneira de crear mapas, de orientarse e de orientar aos lectores nun espazo concreto. O narrador, ao igual que o cartógrafo, establece os límites do espazo que se representará na novela (Turchi, 2004). De feito, "el primer urbanógrafo es el propio autor al trazar con especial meticulosidad el plano de la miseria de Madrid. Un plano en el que se van estableciendo límites entre la ciudad y los suburbios" (Hibbs, 2012: 285).

\section{O diálogo como desencadeante dos espazos proxectados}

La busca (1904), como xa o propio paratexto titular anticipa, trátase dunha obra que narra as peripecias dun adolescente chamado Manuel Alcázar pola capital madrileña da época, que percorre a cidade dende o centro até os arrabaldes.

A acción iníciase na pensión de Dona Casiana, unha casa de hóspedes na que conviven, ademais de Petra e o seu fillo Manuel, a dona da casa, a súa sobriña e os hóspedes que se albergan nela. O relato trasládanos, pois, a un ambiente urbano, identificábel e descrito con gran minuciosidade:

El portal, largo, oscuro, mal oliente, era más bien un corredor angosto, a uno de cuyos lados estaba la portería. Al pasar junto a esta última, si se echaba una 
mirada a su interior, ahogado y repleto de muebles, se veía constantemente una mujer gorda, [...]. Se seguía adelante y, a la izquierda del portal, daba comienzo la escalera, siempre a oscuras [...] (Baroja, 2010: 242-243).

Este primeiro espazo físico constitúe un lugar de ficción que funciona como marco espacial da narración ou setting, xa que é onde se desenvolve a acción nos primeiros catro capítulos da novela. Esta casa de hóspedes localízase na rúa de Mesonero Romanos, como se aclara na nota a rodapé do segundo capítulo desta primeira parte: "El escenario de la novela se sitúa con toda precisión en la calle de Mesonero Romanos, una de las que se sacrificaron para crear la Gran Vía” (Baroja, 2010: 241). Segundo a clasificación socio-xeográfica proposta pola investigadora Iraitz Urkulo (2012), a pensión de Dona Casiana estaría situada nunha das rúas que desembocan na coñecida rúa Gran Vía, a escasos metros da praza de Callao.

Un caso de espazo proxectado prodúcese no capítulo IV desta primeira parte. O estudante Roberto e o ancián Don Telmo inician unha agradábel conversa no interior da pensión. Pero, debido ao balbordo que había na sala onde estaban falando, Don Telmo convida a Roberto ao seu cuarto para poder continuar a conversación nun ambiente máis íntimo: “¿No sigue usted? No, porque no quiero que nadie se entere de lo que yo hablo. Venga usted a mi cuarto, allí hablaremos tranquilamente" (Baroja, 2010: 270). Xa no cuarto do ancián, nun momento da conversa, Roberto lembra un suceso que lle aconteceu anos atrás, dando lugar á proxección espacial do estudante na praza das Descalzas de Madrid:

Hará dos años, por esta época, quise yo hacer un regalillo a una hermana, [...] y se me ocurrió, tres días antes de su santo, comprar dos óperas, encuadernarlas y enviárselas. Yo quería que encuadernasen el libro en seguida, pero en las tiendas donde entré me dijeron que no había tiempo; iba con mis óperas bajo el brazo por cerca de la plaza de las Descalzas, cuando veo en la pared trasera de un convento una tiendecilla muy pequeña de encuadernador, como una covachuela, con escaleras para bajar (Baroja, 2010: 270).

Desta maneira, o personaxe de Roberto, a través da memoria, evoca esta rúa madrileña ao lembrar un acontecemento da súa vida privada. Polo tanto, o desencadeante que provoca a súa proxección espacial é o diálogo que mantén co ancián Don Telmo. O personaxe pasa de estar inserido nun espazo interior, como é a pensión de Dona Casiana, para situarse nun espazo exterior, a praza das Descalzas. 
Outro exemplo de espazo proxectado xorde no capítulo IV da segunda parte. Neste segundo bloque, composto por nove capítulos, a acción trasládase ás aforas de Madrid. Manuel está a traballar na zapatería do señor Ignacio, situada na calle del Águila. Sobre a localización xeográfica deste establecemento, o editor aclara nunha das notas a rodapé o seguinte:

La acción se desplaza del centro de Madrid a las afueras, a los barrios más pobres de los próximos al río Manzanares. La calle del Águila sube desde la ronda de Segovia, cerca de la glorieta de Puerta de Toledo, cruza la Gran Vía de San Francisco y, prolongada con el nombre de calle Tabernillas, desemboca en la plaza de la Puerta de Moros, junto a la de la Cebada (Baroja, 2010: 274).

Un día, Manuel recibe a visita de Roberto. Os dous rapaces deciden ir cear ao café de San Millán para atoparse cun home chamado Don Alonso, máis coñecido como o "Home-boa". O motivo da reunión non é outro que saber se Don Alonso coñece a unha muller chamada Rosita Buenavida: "Quería yo preguntarle si por haber vivido en el mesón del Cuco conocía usted a una tal Rosita Buenavida, volatinera [...] ¿Qué edad tenía la Rosita que conoció usted?" (Baroja, 2010: 335). Esta taberna na que ten lugar a cita dos mozos con Don Alonso funciona como setting ou marco espacial da acción. O personaxe de Don Alonso, durante a súa conversa cos dous adolescentes, recorda diferentes viaxes que fixo a distintas cidades hai anos. Por tanto, o diálogo volve funcionar como desencadeante dun espazo proxectado, neste caso, de varios espazos proxectados como son París, América e La Habana. De novo, Pío Baroja a través da analepse, sitúa ao personaxe en escenarios distintos á taberna:

Pues le diré a usted; yo fui a París el sesenta y ocho, contratado al circo de la Emperatriz [...]. A los cuatro meses, Pérez y yo, Pérez ha sido el gimnasta más grande del mundo, fuimos a América; [...]. Estuvimos en La Habana durante unos ocho meses; trabajando allí, nos salió un negocio de una lotería [...] (Baroja, 2010: 335-336).

Na terceira e última parte da novela, composta por oito capítulos, prodúcense diferentes cambios de escenario debido ao pasamento do pequeno Leandro. De feito, Manuel vese na obriga de abandonar a zapatería do señor Ignacio e buscar un novo traballo e lugar onde vivir. Comeza a traballar na tenda do "tío Patas" até que pouco tempo despois decide deixar o traballo e probar sorte como panadeiro nunha tafona situada na rúa do Horno de la Mata. Neste capítulo III, Manuel acode ao "cuartel de María Cristina” para 
xantar. Alí, mentres espera a súa quenda para ser servido, atópase co estudante Roberto. Os dous mozos deciden dar un paseo polos arredores para conversar. Durante o diálogo, Roberto informa a Manuel que, nun futuro próximo, herdará unha inmensa fortuna que o converterá nunha persoa millonaria. Para poder explicarlle a orixe desta futura riqueza, Roberto evoca as visitas que tivera que facer a determinadas persoas para coñecer a verdadeira historia da suposta herdanza:

Las primeras las hice hace dos años. Un día de Carnaval se me ocurrió la idea. Yo daba lecciones de inglés y estudiaba en la Universidad; con el poco dinero que ganaba tenía que enviar parte a mi madre, y parte me servía para vivir y para las matrículas. Este día de Carnaval, un martes, lo recuerdo, no tenía más que tres pesetas en el bolsillo; llevaba tanto tiempo trabajando sin distraerme un momento, que dije: «Nada, hoy voy a hacer una calaverada; me voy a disfrazar». Efectivamente, en la calle de San Marcos alquilé un dominó y un antifaz por tres pesetas y me eché a la calle, sin un céntimo en el bolsillo. Comencé a bajar hacia la Castellana, y al llegar a la Cibeles me pregunté a mí mismo, extrañado: ¿Para qué habré hecho yo la necedad de gastar el poco dinero que tenía en disfrazarme, cuando no conozco a nadie? (Baroja, 2010: 401).

Polo tanto, o personaxe de Roberto lembra un día de Entroido cando fora alugar un disfrace nunha tenda da rúa de San Marcos. Recorda, tamén, os lugares que percorreu unha vez que estaba disfrazado. En efecto, mediante os recordos do personaxe prodúcese a proxección espacial de Roberto a determinadas rúas do centro da cidade e pasa de estar situado nun lugar dos suburbios, que funciona como setting ou marco espacial, para trasladarse ás céntricas rúas madrileñas tales como San Marcos, o paseo da Castellana ou a praza de Cibeles.

A novela pecha de maneira esperanzadora para o seu protagonista mediante a salvación definitiva de Manuel. A pesar de que durante toda a novela non é capaz de vencer na súa loita pola vida, a última escena fará que Manuel confíe na vitoria logo de decidir incorporarse ao mundo dos traballadores honrados:

Todo el Madrid parásito, holgazán, alegre, abandonaba en aquellas horas las tabernas, los garitos, las casas de juego [...]. Quedaban algunas viejas busconas en las esquinas, envueltas en el mantón, fumando... [...]. Aquella transición del bullicio febril de la noche a la actividad serena y tranquila de la mañana le hizo pensar a Manuel largamente (Baroja, 2010: 455-456). 


\section{Conclusións}

Pío Baroja describe na súa novela o Madrid do século XIX no que se presentan tres ambientes claramente diferenciados: o interior, onde se sitúa a casa de hóspedes de Dona Casiana; o ensanche cos seus arrabaldes e o extrarradio. A acción comeza no primeiro deles e irase desprazando progresivamente ás aforas. La busca, debido ás evidentes referencias topográficas, ilustra moi claramente a relación intrínseca existente entre o mapa e a literatura. Así, en palabras do profesor norteamericano Robert T. Tally Jr. (2012: 3):

Las narrativas sirven para dar sentido, o darle forma, al mundo en cuestiones de significación. En ese caso, las obras literarias tienen una función cartográfica de crear figurativa o alegóricamente una representación del espacio social, en un sentido amplio. A esto es a lo que yo llamo cartografía literaria.

En definitiva, este estudo permitiu achegarnos aos denominados projected spaces, concepto proposto pola especialista Barbara Piatti, e presentar unha breve análise deles na novela de Baroja. Así, todos os espazos proxectados corresponderíanse con aqueles lugares ficcionais evocados polos personaxes a partir de lembranzas e recordos, podendo ser entendidos como espazos construídos na imaxinación dos distintos personaxes e que se producen a partir dun desencadeante, neste caso, da conversa entre eles. En resumidas contas, estes lugares de ficción son mostras evidentes de espazos proxectados creados a partir do diálogo.

Laura Caamaño Pérez Centro Ramón Piñeiro para a Investigación en Humanidades

\section{Bibliografía}

Alexander, Neal. 2015. "On Literary Geography”, en Literary Geographies, n 1, pp. 3-6. https://www.literarygeographies.net/index.php/LitGeogs/article/view/1-2/ pdf_8 [Consulta 23/11/2019].

Baroja, Pío. 2010. La busca. Madrid: Cátedra.

Cabo Aseguinolaza, Fernando. 2004. "El giro espacial de la historiografía literaria", en Bases metodolóxicas para unha historia comparada das literaturas da Peninsula Ibérica (eds. Anxo Abuín González e Anxo Tarrío Varela). Santiago de Compostela: Universidade de Santiago de Compostela, pp. 21-43. 
Celma Valero, María Pilar e González, José Ramón. 2010. "Presentación”, en Lugares de ficción. La construcción del espacio en la narrativa actual (eds. María Pilar Celma Valero e José Ramón González). Valladolid-New York: Cátedra Miguel Delibes, pp. 7-14. http://www.espacios-narrativa-cyl.es/libros/5/narrativa-espacio-cuento/ [Consulta 23/11/2019].

Hibbs, Solange. 2012. "La ciudad como espacio de transgresión y decadencia en la novela finisecular (La trilogía La lucha por la vida de Pío Baroja)", en Anales, n 24, pp. 281-305. https://rua.ua.es/dspace/bitstream/10045/25632/1/ALE_24_16. pdf [Consulta 23/11/2019].

Moretti, Franco. 1999. "Introduction. Towards a Geography of Literature", en Atlas of the European Novel, 1800-1900 (ed. Franco Moretti). New York: Verso Books, pp. 1-2.

Orts Agulló, Eva. 2016. Personaje y espacio urbano en la narrativa de Pío Baroja [Tese de doutoramento]. Córdoba: Servicio de Publicaciones de la Universidad de Córdoba. https://helvia.uco.es/xmlui/bitstream/handle/10396/13224/2016000001288. pdf? sequence $=3$ [Consulta 23/11/2019].

Piatti, Barbara, Rudolf Bär, Hans, Reuschel, Anne-Kathrin, Hurni, Lorenz e Cartwright, William. 2009. "Mapping Literature: Towards a Geography of Fiction”, I4 en Cartography and Art (coords. William Cartwright, Georg Gartner e Antje Lehn). USA: Springer, pp. 179-194. http://www.literaturatlas.eu/files/2012/01/ Piatti2008_ArtAndCartography_Springer.pdf [Consulta 23/11/2019].

Piatti, Barbara, Reuschel, Anne-Kathrin e Hurni, Lorenz. 2009. "Literary Geography - or How Cartographers Open up a New Dimension of Literary Studies", en The 24th International Cartographic Conference (ICC). Congreso levado a cabo en Santiago de Chile. https://icaci.org/files/documents/ICC_proceedings/ ICC2009/html/nonref/24_1.pdf [Consulta 23/11/2019].

Piatti, Barbara, Reuschel, Anne-Kathrin e Hurni, Lorenz. 2013. "Dreams, Longings, Memories - Visualising the Dimension of Projected Spaces in Fiction", en The 26th International Cartographic Conference. Congreso levado a cabo en Dresden, Germany. http://www.literaturatlas.eu/files/2014/01/Piatti_ICC2013_final.pdf [Consulta 23/11/2019].

Rozas Arceo, Alba. 2015. "The Hobbit desde a xeografía literaria crítica. Perspectivas de análise", en Boletín Galego de Literatura, no 47, "Estudos", pp. 5-51. http:// www.usc.es/revistas/index.php/bgl/article/view/2176/3231

[Consulta 23/11/2019].

Tally Jr., Robert T. 2012. "Sobre la cartografía literaria. La narrativa como acto espacialmente simbólico", en Cuadrivio. Crítica, creación y divulgación de la ciencia, 
https://es.scribd.com/document/302670729/Sobre-La-Cartografia-Literaria [Consulta 23/11/2019].

Tang, Chenxi. 2008. The Geographic Imagination of Modernity. Geography, Literature, and Philosophy in German Romanticism. Stanford: Stanford University Press.

Thacker, Andrew. 2005. "The idea of a critical literary geography", en New Formations, $n^{\circ} 57$, pp. 56-73.

Turchi, Peter. 2004. Maps of the Imagination: The Writer as Cartographer. San Antonio: Universidad de Trinity.

Urkulo, Iraitz. 2012. "Clasificación socio-geográfica de la novela La busca de Pío Baroja. Madrid a finales del siglo XIX", en Revista Sans Soleil. Estudios de la Imagen, $\mathrm{n}^{\circ}$ 4, pp. 256-270. http://revista-sanssoleil.com/wp-content/uploads/2012/02/ art-Iraitz-Urkulo2.pdf [Consulta 23/11/2019]. 